\title{
Research into the Diversified Engineering Practice Training System Based on Large-scale Engineering View
}

\author{
Tang Lijun, Zeng Yihui, Wang Shixiong, Ma Hui, Yao Shi, Zhang Yaqin, Xiong Zhangyuan \\ Anhui Wonder University of Information Engineering, Heifei, China, 231201
}

\begin{abstract}
Nowadays large-scale engineering thought and individual multiple space are absent in engineering practice training system, and transmission of knowledge is separated from the practice of technique. Therefore the paper proposes the diversified engineering practice training system based-on the large-scale engineering view. First, it gives a detailed explanation of the kernel of the large-scale engineering view. Second, it formulates the engineering practice training system by means of large-scale engineering thought and diversified selection. Finally it discusses how students accomplish the learning tasks of theory and practice in the practice center of integration of theory and practice and social large-scale engineering enterprise against the background of large-scale engineering.
\end{abstract}

KEYWORD: Large-scale Engineering Thought; Diversification; Engineering Practice Training System; Integration of Theory and Practice

\section{INTRODUCTION}

American engineering education has witnessed "technique mode" and "science mode", is undergoing the practice of "engineering mode" and continues to carry forward exploration and reform into future development. "Large-scale engineering view" integrates the factors of science, technique and non-technique, forms a complete engineering activity system, and lays stress on the control of diversified value, aiming to realize the integration of diversified value. As a result, the integration of person, value, society and environment can be realized, and an artificial entity of engineering practice can be created (xiaozhen, 2008). Only has a person set up "large-scale engineering view" at first, then he can realize his own diversified value selection, locate his own place in engineering practice, and realize the harmonious development of social value and individual value.

\section{CONNOTATION OF LARGE-SCALE ENINEERING VIEW}

In 1990s, Moses, then president of College of Engineering, Massachusetts Institute of Technology, proposed large-scale engineering view. The view includes grand or complicated engineering field of vision, multidisciplinary field of vision in engineering, and scientific basic qualities, as well as corresponding humanistic feelings and engineering organization qualities. According to Moses, "largescale engineering view" requires that engineering education should provide students with comprehensive knowledge background, emphasize the practice of engineering and cultivate students' innovation. The teaching reform of higher engineering education in China aims to cultivate engineering talents who are adapted to the need of social economy, scientific technique and cultural development in the 21th century against the background of the large-scale engineering educational view. "Large-scale engineering view" emphasizes three kinds of new abilities or qualities, including engineering practice ability, comprehensive knowledge background and holistic thinking pattern, and professional ethics and social responsibility. The three abilities are cultivated by means of classroom teaching and practice teaching. Practice teaching, in particular, should not deal with engineering discipline teaching in simple isolation, but integrate theoretical knowledge of engineering discipline and practice of technique ( peigen,2011). 


\section{THE PROBLEMS WITH ENGINEERING PRACTICE TRAINING SYSTEM}

\subsection{Lack of large-scale engineering thinking pattern}

Large-scale engineering thinking pattern aims to integrate holistic approach and practice feasibility, and integrate engineering and other disciplines. In such a changing world, a large quantity of scientific inventions develops into marginalization and interdisciplinary integration. For example, engineering mechanics and biological engineering can be integrated. Therefore it is very important to form large-scale engineering view, which emphasizes knowledge is interlinked, holistic and integrated. Those who lack the large-scale engineering thought will find it difficult to get the breakthrough to creation in their major (laibin, 2009).

\subsection{Lack of individual multi-selection space}

According to the large-scale engineering view, the factor of person should be given full consideration, for only a healthy person with individuality can make contribution to the society. In many universities, students majoring in engineering are offered dogmatic theory lecture and formalized practice skill, and participate in teaching activities according to the teacher's given plan without the opportunity for individual selection. So they cannot select learning mode according to their own interest. From the universities without individual selection, the graduates cannot have creation and imagination just as a person is dancing with fetters.

\subsection{Separation of knowledge transmission from technique practice}

Engineering discipline involves the application of physic laws to analysis, design, production and maintenance for engineering system, and the research into development, design, production, installment and maintenance of all the theories and practical problems based on technique experience from production and practice. It is a discipline emphasizing integration of theory and practice. Nowadays the students majoring in engineering have much too theoretic knowledge, but they lack practical ability. The creation in engineering cannot be separated from integration of theory learning and technique practice. The teaching pattern of knowledge emphasizes that knowledge features logic, ladder-type and combination. Knowledge can be transmitted to students, but creation derives from practice. Lecture of knowledge and practice are often separated in universities, and students often forget theoretical knowledge while in practice(Shuguang \& Xinsheng, 2013).

\section{CONSTRUCTION OF DIVERSIFIED ENGINEERING PRACTICE SYSTEM BASED ON LARGE-SCALE ENGINEERING VIEW}

Due to the problems mentioned above in engineering discipline, the paper proposed the diversified engineering practice system based on large-scale engineering view to solve the problems. First, students majoring in engineering discipline should cultivate and form large-scale engineering thought, and comprehend the holistic feature of engineering and knowledge required in engineering industry, i.e. cultivate grand or complicated engineering field of vision, develop multidisciplinary field of vision in engineering and scientific basic qualities, and form humanistic feelings and engineering organizational qualities. Guide students to learn the common points of large-scale engineering and the individualities of concrete engineering disciplines, which is analogous to visiting Lushan Mountain. If a visitor observes the mountain from a far distance, he can comprehend the holistic nature of Lushan Mountain, know the every detail of the mountain, and understand the integration relationship between part and whole. Second, students select the direction of engineering major, cooperation group, and courses and topics according to their own interest. Finally, students apply the learned knowledge to use and creation on practice platform of integration of theory and practice and in social engineering practice.

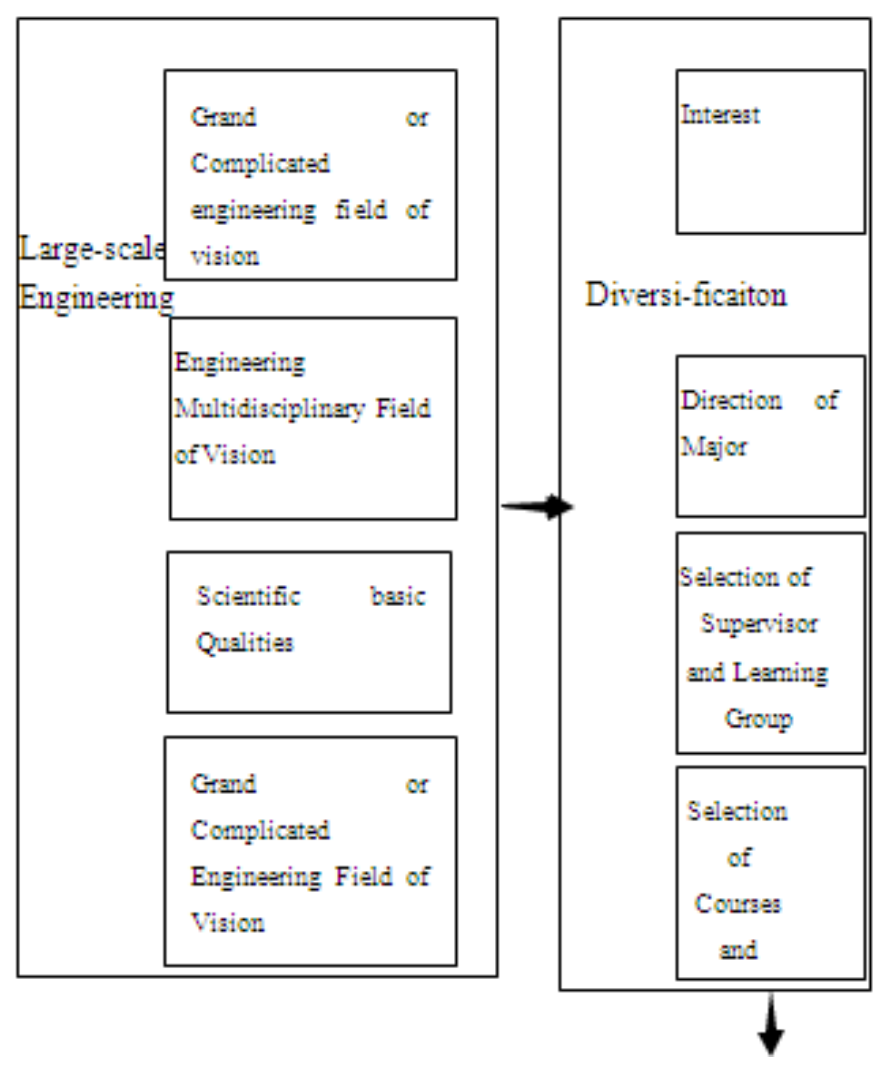




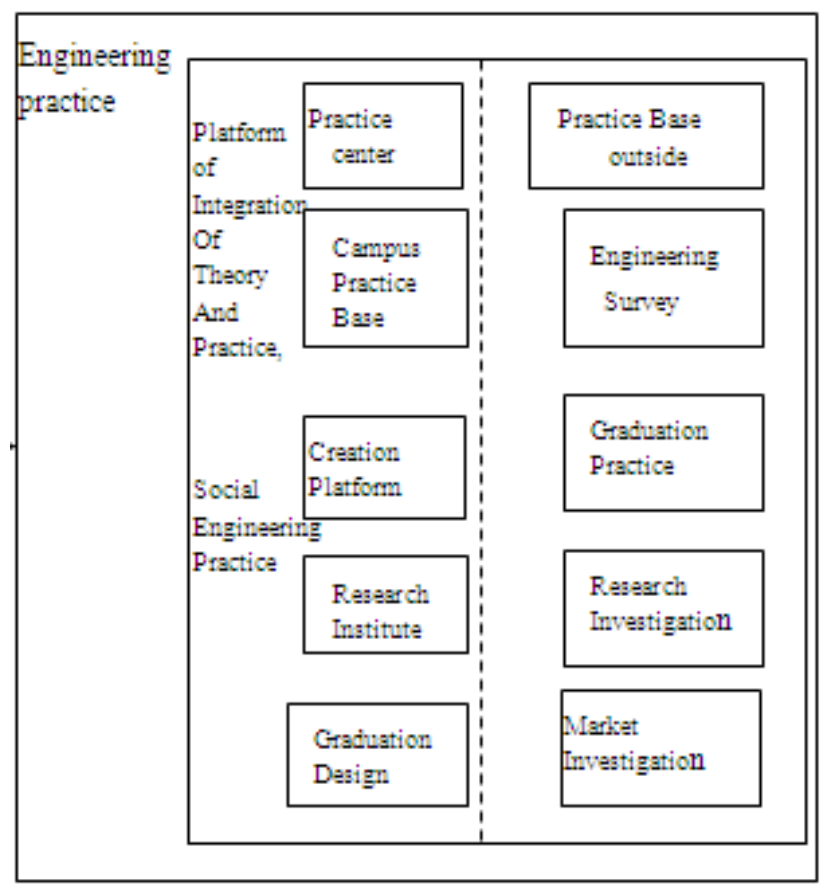

Figure 1.Diversified Engineering Practice System Based on Large-scale Engineering View

\subsection{Cultivation of engineering talents from universality to individuality}

LEngineering, in essence, is the integration of multidisciplinary, the restructured and integrated knowledge system consisting of one or several kernel specialty technique together with corresponding complementary specialty technique, and a created new entity. Engineering activities are knowledge of practice, aiming to solve practical problems. They can be used for definite special economy purpose and social service. They not only have powerful and integrated knowledge attributes, but also have powerful industrial economy attributes. Modern engineering develops into large-scale and integration, taking on the tendency of techniqueintensive integration. Meanwhile large-scale engineering exerts great influence on environmental ecology, humanity, politics, and economy. Therefore "large-scale engineering view", in essence, integrates science, technique, non-technique, engineering practice, featuring practice, integration and innovation (xiaozhen, 2008). This is universality of large-scale engineering. The height of universality, for students, determines that of individuality. Universities should guide students to comprehend, lay store by, and grasp the universality.

Universality requires the creation of individuality, for individual development of talents can meet the social requirement. Universities should build diversified selection mechanism for individual selection of engineering, build and put into effect the practice system of science and research that runs through the whole process of cultivation, and guide students to participate in scientific and research activities, thus promoting students' practical ability and innovation spirit. Since the period of freshmen, students can select innovative experiment plans according to their own interest. Universities may give students the access to innovative experiment projects, and lay a solid foundation for the cultivation of the talents for contests at various levels. Universities should take into full consideration the continuation and expanding of projects while designing experiment projects. Those who have achieved success in projects are encouraged to apply to innovation practice projects at university level. Likewise, those who have accomplished projects at university level are guided to apply practice projects at higher level. The practice cultivates students to have the ability to find, analyze and solve engineering practice problems by means of scientific methods and views, and current technology, tools or new technology (Yan, Benlian, Qi, Jingbo, 2013; Hongliang \& Changchun, 2012). Through offering students corresponding practice credits, universities guide students to visit advanced technology exhibition, attend lectures at the leading edge of various disciplines and participate in academic exchange activities, so that students can broaden the field of vision, learn the knowledge and in-formation of disciplines, stipulate learning enthusiasm, find out learning interest, and strengthen learning vigor. Meanwhile universities encourage students to participate in technique training and various kinds of qualification certification organized by well-known enterprises at home and abroad in order to cultivate their professional ethics and specialty technique. Universities encourage students participate in parttime social practice projects, and improve the ratio of market research, business practice and management practice in social practice to guide students to start an undertaking or develop into talents.

\subsection{High integration of theory and practice}

Theory and practice can be integrated from the following two aspects.

Build training center of practice teaching for integration of theory and practice. Most courses in engineering disciplines are taught in the form of integration of theory and practice, but the traditional teaching separates theory lecture and practice. In our university, the integration of theory and practice is carried out in engineering disciplines. There are five practice workshops in the modern practice center, including the numerical control workshop equipped with 24 numerical control machines, the metalworking shop with 44 machine tools, the fitting shop with 60 stations, welding shop with electric welding and oxygen welding, and assembling workshop. There are 12 professional laboratories, including NC Simulation Laboratory, Virtual 
Manufacturing Laboratory, Laboratory of Mechanical Principle, Mechanical Parts Laboratory, Mechanical and Electrical Integration Laboratory, MPS Automated Production System Laboratory, Hydraulic and Pneumatic Laboratory, Digital Circuit and Analog Circuit Laboratory, PLC Laboratory, MCU Laboratory, etc. The Experiment Platform for Integration of Theory and Practice in Mechanical and Electrical Integration Laboratory is invested almost 10 million, which is seldom found in Anhui Province. In the various practice centers, laboratories, bases, workshops mentioned above, teachers may integrate perceptual materials and rational knowledge so that students can apply the engineering knowledge to practice. It is the process of doing while learning, and learning while doing.

Practice is carried out in the society of large-scale engineering against the background of large-scale engineering industry. Our university has established long-term cooperation relationship with some largescale engineering companies, like Zhongding Group, thus having in-depth cooperation from multiperspectives. As a result, students can comprehend and apply the theoretical knowledge to practice under the circumstances of large-scale engineering, and accomplish the transfer from learning in universities to practice in society by means of periodic practice, graduation practice, engineering survey, scientific research investigation, latitudinal projects, etc.

\section{CONCLUSION}

Only those who have large-scale engineering thought can clearly appraise the accuracy and practice of their own engineering major. Otherwise it is bind. Under the circumstances of forming large-scale engineering view, a person can locate the position of large-scale engineering industry for his own development and put what he learned to practice on condition that he can integrate engineering knowledge and practice.

\section{ACKNOWLEDGEMENT}

The work was supported by The Education Department of Anhui Province, Teaching Reform and Quality Promotion Plan [2013zdjy158]; Practice Education Base Project of Cooperation between University and Enterprise Approved by Anhui Province Office of Education, Project No.:[2013jyxm588]; Comprehensive Major Reform Pilot Project of Rejuvenation Plan Approved by Anhui Province Office of Education, Project No.: [2013zy088]; Teaching Reform Research Project of Anhui Province Higher Education, Project No.: [2012jyxm591]; Model Experiment and Practice Center Project of Rejuvenation Plan Approved by Anhui Province Office of Education, Project No.: [2013sxzx025].

\section{REFERENCES}

[1] LI Ming and LEI Yuan-zhong A Vision of the priority fields of mechanical engineering during Tenth Five-Year. Chinese Journal of Mechanical Engineering, 2001(37): 14.

[2] WU Shu-guang and LI Xin-sheng. The construction of higher vocational teaching model upon "knowledge+skills". Vocational and Technical Education, 2013(5): 29-31.

[3] XIE Wen-ming. Exploration and Analysis of theorypractice integration model under the school- enterprise cooperation mechanism. Vocational and Technical Education, 2011(32): 34-36.

[4] JUE Li. Exploration and Research of laboratory construction upon theory-practice integration. Journal of China Adult Education, 2010(12): 35-36.

[5] LIU Meng-qin. The construction of diversified practical teaching system with innovation training as the core. Research and Exploration in Laboratory, 2014(33): 189193.

[6] WANG Dan, A study of practice-based practical teaching system in higher vocational colleges. Research and Exploration in Laboratory, 2014(6): 75-78. 